\title{
Índice de Vulnerabilidade Ambiental na Microbacia do Talhado, Santa Luzia, Paraíba
}

\author{
Fellipe Ragner Vicente de Assis ${ }^{a}$, Joedla Rodrigues de Lima ${ }^{a^{*}}$, José Evanaldo Rangel da Silvaa, Izaque Francisco \\ Candeia de Mendonçab \\ a Programa de Pós-Graduação em Ciências Florestais, Universidade Federal de Campina Grande, Patos, 58708-110, Paraíba, Brasil. \\ *joedlaima@yahoo.com.br \\ b Unidade Acadêmica de Engenharia Florestal, Universidade Federal de Campina Grande, Patos, 58708-110, Paraíba, Brasil.
}

Recebido: 10 junho 2017 / Aceito: 10 julho 2017 / Publicado online: 27 setembro 2017

\begin{abstract}
Resumo
O Índice de Vulnerabilidade Ambiental é uma ferramenta primordial na investigação e identificação dos fatores que podem gerar degradação ambiental em ecossistemas, como as bacias hidrográficas. Diante do exposto, o objetivo deste estudo foi determinar o Índice de Vulnerabilidade Ambiental na microbacia hidrográfica do Talhado, localizada no município de Santa Luzia, Paraíba. Para aplicação da metodologia, o Índice de Vulnerabilidade Ambiental foi gerado pela soma dos seguintes planos de informações: índice de vegetação por diferença normalizada, fator topográfico, uso atual da terra e áreas de preservação permanente e uso restrito. Estes planos foram criados utilizando um sistema de informações geográficas que utilizou o Idrisi Andes, versão 16.0. Os resultados mostraram que 581,2 hectares $(49,9 \%)$ da microbacia foram identificados com vulnerabilidade moderada, seguida pelas áreas com vulnerabilidades baixa e muito baixa com 541,4 hectares (46,5\%), enquanto que 41,1 hectares $(3,5 \%)$ apresentaram vulnerabilidade que variaram de grave a muito grave. Tais resultados indicam atenção especial que deve ser dada ao manejo conservacionista dos recursos naturais na Microbacia do Talhado, Paraíba.
\end{abstract}

Palavras-chave: degradação dos solos, recursos naturais, semiárido

\section{Environmental Vulnerability Index in the Micro-watershed of Talhado, Santa Luzia, Paraíba}

\begin{abstract}
The environmental vulnerability index is a vital tool in the investigation and identification of factors which may generate environmental degradation in ecosystems, such as the watersheds. In view of what has been exposed here, the objective of this study was to determine the environmental vulnerability index in the micro-watershed of Talhado, in the municipality of Santa Luzia, Paraíba. For the application of the methodology, the environmental vulnerability index was generated by the addition of the following information plans: normalized difference vegetation index, topographical factor, current land use, permanent preservation areas and restricted use; which were created using a geographical information system, which encompassed Idrisi Andes, version 16.0. The results showed that 581.2 hectares $(49.9 \%)$ of the micro-watershed were identified with moderate vulnerability, followed by areas of 541.4 hectares $(46.5 \%)$ with low and very low vulnerabilities, while 41.1 hectares $(3.5 \%)$ varied from serious to very serious. These results indicate that special attention must be given to the conservationist management of its natural resources on Talhado's micro-watershed.
\end{abstract}

Keywords: land degradation, natural resources, semiarid land

\section{Introdução}

O estudo de vulnerabilidade está intrinsecamente ligado ao dos desastres, e este último corresponde à reunião de um evento extremo natural, associado à presença humana e ao grau de vulnerabilidade de uma pessoa ou de um grupo de pessoas. Não ocorrerá um desastre natural sem danos pessoais, neste sentido, reconhecer o grau de vulnerabilidade de uma população exposta a riscos naturais permite que ações de governos ou instituições sejam orquestradas para evitar danos ou desastres (Wisner et al., 2004).
Segundo Milanezi e Pereira (2016) “a vulnerabilidade está sempre relacionada à maior ou menor fragilidade de um determinado ambiente". Considerando o aumento populacional e consequentemente maior exposição aos riscos naturais este estudo tem grande relevância para que as sociedades possam responder de forma satisfatória, minimizando eventos de fome, doenças, falta de abrigo e segurança.

O estudo da vulnerabilidade está atrelado à diversas áreas do conhecimento e encontra-se subdividida em 
vulnerabilidade natural, ambiental, social e socioambiental (Zanella et al., 2013). A vulnerabilidade de um ambiente se constrói por meio de eventos adversos à sustentabilidade do meio, e resultam de fatores socioeconômicos e ambientais, incluindo as características do meio físico.

No semiárido brasileiro, o evento natural a que a população está exposta são as secas, entretanto este é um evento cíclico e que toma proporção de desastre porque a forma de lidar com o ambiente natural foi marcada pelo modelo de exploração adotado durante a colonização e que perdura até hoje.

Esta região se caracteriza por solos predominantemente argilosos, rasos e pedregosos, vegetação xerófita, adaptada às condições edafoclimáticas. O semiárido rural apresenta práticas rudimentares agrícolas e pecuárias, com o agravante da acentuada desigualdade social, fatores que contribuem para a vulnerabilidade ambiental regional.

No semiárido paraibano pode-se concluir que se verificam "alterações negativas nas propriedades químicas, físicas e biológicas dos solos" e a "degradação da vegetação, que compreende a redução no número das espécies e na composição vegetativa" (Abdi et al., 2013, p. 41).

$\mathrm{Na}$ identificação das causas geradoras do processo de vulnerabilidade, o estudo em nível de bacia hidrográfica permite a inter-relação dos elementos bióticos e abióticos, num ambiente delimitado naturalmente por divisores de água, com um ponto de saída da água, o exutório, constituindo-se numa unidade ecossistêmica, segundo Sousa e Nascimento (2015) esta unidade de estudo favorece que se privilegie o ecossistema como objeto de análise.

A gestão racional das práticas de uso e manejo das bacias hidrográficas, permite que se preserve os recursos naturais e os serviços a eles associados garantindo qualidade de vida ao ser humano (Porto e Porto, 2008). Uma ferramenta importante é a utilização das tecnologias espaciais como o sensoriamento remoto, aliado aos Sistemas de Informação Geográfica (SIG's), para analisar a dinâmica da cobertura vegetal e do uso do solo (Pons e Pejon, 2008).

Este estudo se propõe contribuir na investigação e identificação dos fatores da degradação e vulnerabilidade ambiental em região semiárida, considerando que os resultados podem favorecer a tomada de decisões pelos poderes públicos frente aos possíveis danos ambientais intensificados pela ação humana, principalmente quando se adota a bacia hidrográfica como unidade de diagnóstico ambiental.

Diante do exposto, o objetivo do presente trabalho foi determinar o Índice de Vulnerabilidade Ambiental (IVA) na microbacia hidrográfica do Talhado, município de Santa Luzia, Paraíba.

\section{Material e Métodos}

A pesquisa foi desenvolvida na microbacia do rio Talhado, com 1164,7 ha., que está circunscrita entre as coordenadas geográficas, $36^{\circ} 54^{\prime} 39^{\prime \prime}$ a $36^{\circ} 57^{\prime} 07^{\prime \prime}$ de longitude oeste e 6 $6^{\circ} 59^{\prime} 08^{\prime \prime}$ a $7^{\circ} 02$ ' $12^{\prime \prime}$ de latitude sul (Figura 1).

Sendo importante contribuinte do rio Quipauá, principal curso de água que drena o município de Santa Luzia, PB e desagua no rio Seridó, este no rio Espinharas, integrantes da bacia Piranhas-Açu que desagua no Rio Grande do Norte.

O clima da região é do tipo BSh de baixa latitude e altitude (Alvares et al. 2014). A pluviosidade média anual é de 547,8 $\mathrm{mm}$, e concentra-se entre os meses de janeiro a abril (AESA, 2017). A vegetação predominante na região é do tipo caatingaseridó. (Alves et al., 2011).

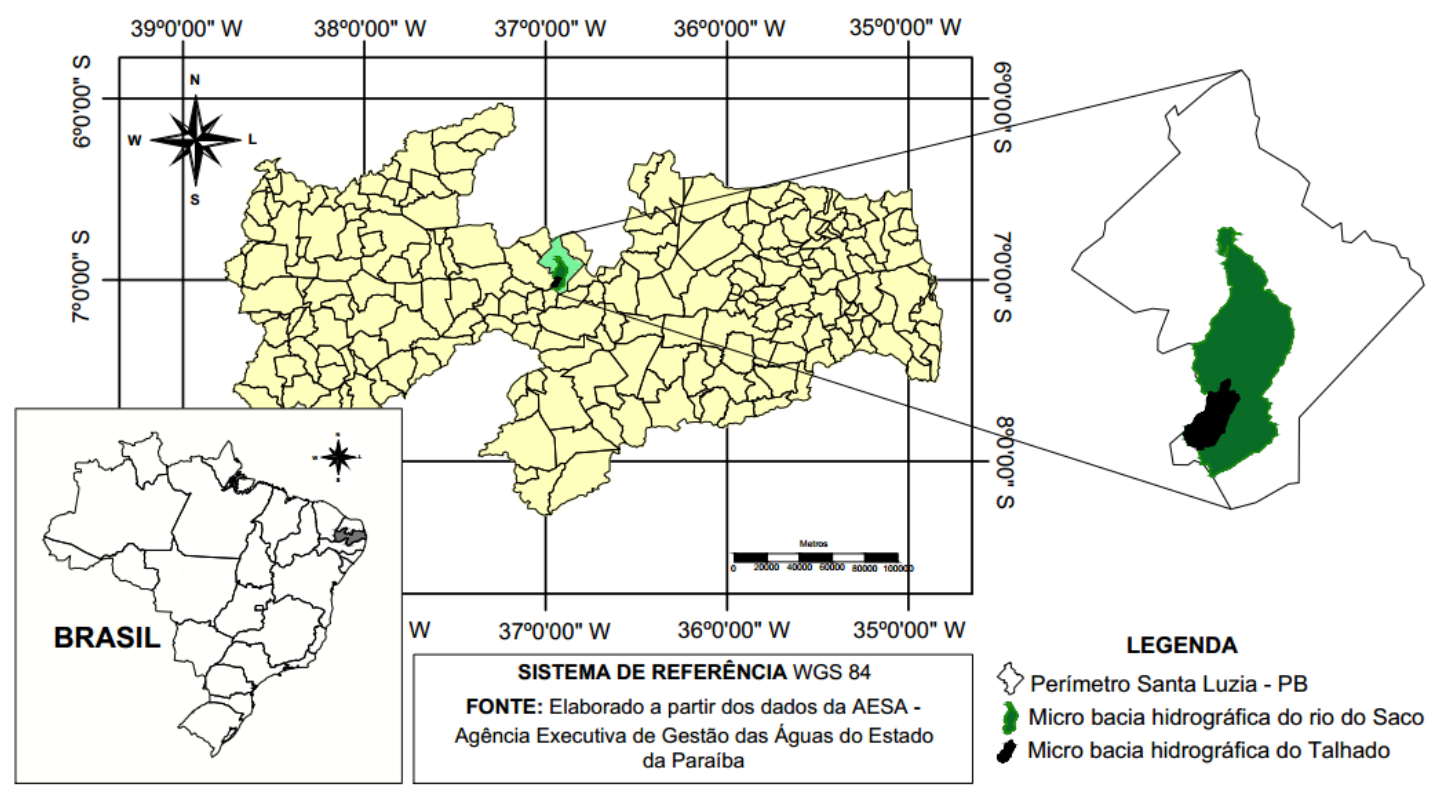

Figura 1. Localização Geográfica do Estado da Paraíba, destacando o município de Santa Luzia, a micro bacia hidrográfica do rio do Saco e a microbacia hidrográfica do Talhado.

Na microbacia do Talhado há predominância de Neossolos Litólicos Distrófico e Eutrófico e, em menor proporção, de
Neossolos Flúvicos, sendo geologicamente a área formada pelas unidades litoestratigráficas: Suíte Várzea Alegre 
(litotipos: Granito e Granidiorito) e Serra dos Quintos com os litotipos: Clorita Xisto, Xisto, Gnaisse, Termolita-clorita xisto e Metabasalto (Marcelino, 2012).

A metodologia utilizada na presente pesquisa fundamentou-se nos trabalhos desenvolvidos por Melo e Lima (2012), Pinese Júnior e Rodrigues (2012), e Silva et al. (2010), visto que estes autores, consideraram os principais fatores físicos e antrópicos atuantes à vulnerabilidade ambiental.

Para a determinação do Índice de Vulnerabilidade Ambiental (IVA) foram definidos os seguintes Planos de Informações (PI's): Índice de Vegetação por Diferença Normalizada, fator topográfico, uso atual da terra e espacialização das áreas legais previstas pela Lei $N^{\circ} 12.651$ de 25 de maio de 2012.

Com relação ao Índice de Vegetação por Diferença Normalizada (NDVI), foram estabelecidas classes de vegetação, resultante das respostas obtidas no NDVI, para dois anos distintos (2010 e 2013), tornando possível a análise da variabilidade da cobertura vegetal neste período. Para sua realização utilizou-se as imagens do satélite ResourceSat-1, sensor "LISS3", órbita 337, ponto 081, bandas espectrais 3 (vermelho) e 4 (infravermelho próximo), com datas de passagem em 28 de dezembro de 2010 e 27 de fevereiro de 2013, respectivamente. Para unificar o DN (Digital Number) das bandas 3 e 4, para comparar o NDVI no período estudado, realizou-se a conversão da escala de cinza para a escala radiométrica, empregando-se os valores de radiância mínima (b3=0; b4=0) e máxima $(b 3=15,131 ; b 4=15,757)$ do sensor LISS3 do Satélite ResourceSat-1.

O NDVI foi calculado pela a razão entre a diferença da reflectância das bandas do infravermelho próximo e vermelho pela soma dessas mesmas bandas (Rouse et al., 1974), segundo a equação abaixo, onde: $\rho 4$ - Infravermelho próximo $(0,76$ a $0,90 \mu \mathrm{m}) ; \rho 3$ - Vermelho $(0,63$ a $0,69 \mu \mathrm{m})$

$$
N D V I=\frac{(\rho 4-\rho 3)}{(\rho 4+\rho 3)}
$$

Em seguida, para avaliar a variabilidade do índice de vegetação entre diferentes anos, realizou-se operação de subtração (imagem diferença) entre os mapas de NDVI de 2010 e 2013, determinando, assim, 5 classes de vulnerabilidade ambiental (Tabela 1), correspondendo às classes temáticas de desmatamento/redução da cobertura vegetal ( 2 classes), manutenção de cobertura vegetal (1 classe) e regeneração/incremento de vegetação (2 classes), para as quais foi levado em consideração os valores da média $(\mu)$, da distribuição dos níveis de cinza da imagem e do desvio padrão (Sd), adaptado de Louzada et al. (2009).

O Fator topográfico (LS), foi determinado a partir da equação desenvolvida por (Bertoni e Lombardi Neto, 1990).

O comprimento de vertente foi gerado a partir dos planos de informações, mapa de aspecto e do Modelo Digital do Terreno (MDT) do projeto Advanced Spaceborne Thermal Emission and Reflection Radiometer Global Digital Elevation Model (ASTER GDEM).

O plano de informação declividade, também obtida através do MDT, foi reclassificado a partir da adaptação da classificação utilizada por Ramalho Filho e Beek (1995).
Tabela 1. Classificação da vulnerabilidade ambiental segundo o Índice de Vegetação por Diferença Normalizada

\begin{tabular}{lccc}
\hline \multicolumn{1}{c}{ Classe } & Tema & Vulnerabilidade & Coeficiente \\
\hline$] 2 \mathrm{Sd}, \mu+2 \mathrm{Sd}]$ & $\mathrm{Iv}$ & Muito baixa & 1 \\
{$[\mu+2 \mathrm{Sd}, \mu+\mathrm{Sd}]$} & $\mathrm{Iv}$ & Baixa & 2 \\
{$[\mu+\mathrm{Sd}, \mu-\mathrm{Sd}]$} & $\mathrm{Mv}$ & Moderada & 3 \\
{$[\mu-\mathrm{Sd}, \mu-2 \mathrm{Sd}]$} & $\mathrm{Rv}$ & Grave & 4 \\
{$[\mu-2 \mathrm{Sd},-2 \mathrm{Sd}[$} & $\mathrm{Rv}$ & Muito grave & 5 \\
\hline
\end{tabular}

Sd: desvio padrão. Temas: Iv - Incremento de vegetação; Mv Manutenção de vegetação; Rv - Redução de vegetação. Fonte: Adaptado de Louzada et al. (2009).

Por fim, o comprimento de vertente e a declividade foram implementados à fórmula de fator topográfico, descrita anteriormente, sendo que a amplitude encontrada para o mapa de fator topográfico foi distribuída em 5 classes de níveis de vulnerabilidade ambiental (tabela 2 ).

Tabela 2. Classificação da vulnerabilidade ambiental segundo o fator topográfico (LS).

\begin{tabular}{lcc}
\hline \multicolumn{1}{c}{ Classe de LS } & Vulnerabilidade & Coeficiente \\
\hline 0,000 a 1,214 & Muito Baixa & 1 \\
1,214 a 2,428 & Baixa & 2 \\
2,428 a 3,642 & Moderada & 3 \\
3,642 a 4,856 & Grave & 4 \\
4,856 a 6,07 & Muito Grave & 5 \\
\hline
\end{tabular}

O plano de informação do uso atual da terra para a microbacia do Talhado, foi gerada a partir de uma classificação visual de imagem do satélite ResourceSat-2, sensor "LISS3", órbita 337, ponto 081, bandas 2, 3 e 4, com data de passagem em 27 de fevereiro de 2013. A imagem foi georreferenciada utilizando pontos de controle geométricos coletados na imagem ortorretificada da NASA (GLS 2005 do Landsat-5, sensor TM e ETM). Gerou-se uma composição colorida 2B4G3R para melhorar a visualização e identificação dos alvos de interesse e atualizou-se a classificação visual.

Após a determinação do mapa de uso atual da terra, procedeu a distribuição das tipologias em classes (Tabela 3), de acordo com a influência que cada uso contribui para a vulnerabilidade ambiental.

Tabela 3. Classificação da vulnerabilidade ambiental segundo as classes de uso atual da terra

\begin{tabular}{lcc}
\hline \multicolumn{1}{c}{ Classes de uso } & Vulnerabilidade & Coeficiente \\
\hline $\begin{array}{l}\text { Afloramentos rochosos } \\
\text { Corpos d'água }\end{array}$ & Nula & 0 \\
$\begin{array}{l}\text { Caatinga Arbustiva Arbórea } \\
\text { Fechada + Algaroba }\end{array}$ & Baixa & 1 \\
$\begin{array}{l}\text { Caatinga Arbustiva Arbórea } \\
\text { Aberta }\end{array}$ & Moderada & 3 \\
$\begin{array}{l}\text { Pastagem + Agricultura } \\
\text { Extração Mineral }\end{array}$ & Grave & 4 \\
\hline
\end{tabular}

Fonte: Silva (2014). 
Esta distribuição, partiu do princípio, que quanto mais o solo estiver exposto (menor cobertura vegetal) e mais antropizada a área, maior será a sua vulnerabilidade. Para o tema corpos d'agua, verifica-se que para a região semiárida à medida que o nível da água gradativamente vai diminuindo nos meses de estiagem, há utilização de suas margens para diversos usos (pastagem, agricultura, entre outros), atribui-se peso mínimo (muito baixa), de acordo com Silva (2014).

A determinação das Áreas de Preservação Permanente (APP) e uso restrito consistiram da espacialização das Áreas Legais prevista pela Lei $\mathrm{N}^{\circ} 12.651$, de 25 de maio de 2012 (Brasil, 2012), que dispõe sobre a proteção da vegetação nativa.

Para a espacialização das Áreas Legais, inicialmente digitalizou-se a rede de drenagem, corpos d'água e a área da microbacia do Talhado a partir da Carta Planialtimétrica da SUDENE, editada em 1985 e digitalizada em 1996; Folhas de Jardim do Seridó - RN (SB.24 - Z - B - V) e Juazeirinho PB (SB.24-Z - D - II), na escala 1:100.000; MDT do projeto Advanced Spaceborne Thermal Emission and Reflection Radiometer Global Digital Elevation Model (ASTER GDEM); e, Imagem do satélite ResourceSat-2, sensor "LISS3", órbita 337, ponto 081, bandas 2, 3 e 4, com data de passagem em 27 de fevereiro de 2013.

Após a vetorização da drenagem e corpos d'água, aplicouse as normas da legislação ambiental vigente. Para as áreas de uso restrito e encostas empregou-se o MDT de 30 metros, antes foi gerado o mapa de declividade da área. A obtenção dos planos de informações e do mapa do Índice de Vulnerabilidade Ambiental se deu por meio de algoritmos implementados em módulos específicos de desenho por computador e o Idrisi (EASTMAN, 2016).

Por fim, atribuiu-se um coeficiente para cada conflito de uso de acordo com sua influência à vulnerabilidade ambiental (Tabela 4), onde o fator preponderante para a atribuição dos pesos foi a declividade do terreno, sendo que as áreas que apresentaram sobreposição de declividades acentuadas com APP de drenos, foram atribuídas maior peso, uma vez que, além da influência da inclinação do terreno, os drenos são áreas de maior velocidade de escoamento superficial de água das chuvas, e potencialmente mais vulneráveis à degradação.

Tabela 4. Classificação da vulnerabilidade ambiental segundo as Áreas de Preservação Permanente e Uso Restrito, segundo Brasil, 2012

\begin{tabular}{lcc}
\hline Classe de Conflito & \multicolumn{2}{c}{ Vulnerabilidade Coeficiente } \\
\hline APP de Drenos & Muito Baixa & 1 \\
Uso restrito & Baixa & 2 \\
APP de Drenos + Uso restrito & Moderada & 3 \\
Declividade $>45^{\circ}$ & Grave & 4 \\
APP de Dreno + Declividade & Muito Grave & 5 \\
\hline $45^{\circ}$ & \\
\hline
\end{tabular}

Para o Índice de Vulnerabilidade Ambiental (IVA), utilizou-se a metodologia de Silva et al (2010), que integra todas as variáveis anteriores. Após a integração dos planos de informações, o mapa digital do Índice de Vulnerabilidade Ambiental foi elaborado e reclassificado para se obter 5 classes potenciais à vulnerabilidade ambiental (Tabela 5).

Tabela 5. Classificação do Índice de Vulnerabilidade Ambiental segundo a integração dos planos de informações

\begin{tabular}{lcc}
\hline \multicolumn{1}{c}{$\begin{array}{c}\text { Somatório dos } \\
\text { Mapas preliminares }\end{array}$} & Vulnerabilidade & Coeficiente \\
\hline 4 a 6,4 & Muito Baixa & 1 \\
6,4 a 8,8 & Baixa & 2 \\
8,8 a 11,2 & Moderada & 3 \\
11,2 a 13,6 & Grave & 4 \\
13,6 a 16 & Muito Grave & 5 \\
\hline
\end{tabular}

Fonte: Silva et al (2010).

\section{Resultados e discussão}

A análise dos histogramas das imagens NDVI obtidas indica a predominância dos valores concentrados em torno da média, 0,352 e 0,037 (2010 e 2013) respectivamente, mostrando diminuição da média e da amplitude de radiância do NDVI de 2013, comparado a 2010, indicando assim, redução da cobertura florestal.

A partir da imagem-diferença, foi possível evidenciar as mudanças ocorridas entre os dois períodos selecionados e assim determinar o potencial de vulnerabilidade ambiental (Figura 2). Verificou-se que maior parte da área $(782,3$ ha $67,23 \%)$ apresenta índice de vulnerabilidade moderada, distribuída no limiar $[\mu+\mathrm{Sd}, \mu-\mathrm{Sd}]$, indicando estabilidade na cobertura florestal e que apresenta situação inalterada.

As áreas que indicaram redução/desmatamento da cobertura vegetal ( $\mathrm{Sd}<-1$ da média/DV), classificadas com vulnerabilidade grave e muito grave, apresentaram área total de 258,6 ha $(22,22 \%)$. Com relação às áreas de incremento da vegetação (classes de distribuição maior que $+1 / \mathrm{DV}$ ), classificadas com vulnerabilidade baixa e muito baixa, quando somadas apresentaram uma área total de 122,8 ha $(10,55 \%)$.

Considerando as mudanças no índice de vegetação, toda a área de estudo sofreu uma mudança negativa, uma vez que a frequência na distribuição dos valores abaixo de -1/DV foi maior do que a frequência na distribuição acima de +1/DV. Estas áreas que sofreram redução, necessitam de medidas mitigadoras, pelo potencial à vulnerabilidade ambiental.

É possível que os resultados no período avaliado tenham sido influenciados pelas precipitações médias, da área de estudo nos dois períodos, considerando que o bioma caatinga é fortemente afetado pela presença ou ausência de chuvas (Silva, 2014). No trimestre que antecedeu a obtenção da imagem de 2010, choveu 122,4 mm, enquanto que na imagem de 2013 , choveu $55,4 \mathrm{~mm}$, apenas $46 \%$ do ano anterior (Tabela 6). Fato que é ainda consolidado pela precipitação acumulada para o ano de $2010(546,4 \mathrm{~mm})$, bem abaixo dos 190,8 mm precipitados no ano de 2010 (considerou-se 2012, porque a imagem utilizada foi de 27 de fevereiro de 2013, recebendo maio influência climática de 2012).

Quanto à vulnerabilidade identificada por meio do fator topográfico (LS; Figura 3), verificou-se o relevo movimentado como característica marcante da geomorfologia da microbacia do Talhado. Os resultados indicam que 713,4 ha $(61,31 \%)$ da área, apresenta Índice de Vulnerabilidade Ambiental que varia de moderada a muito grave. 


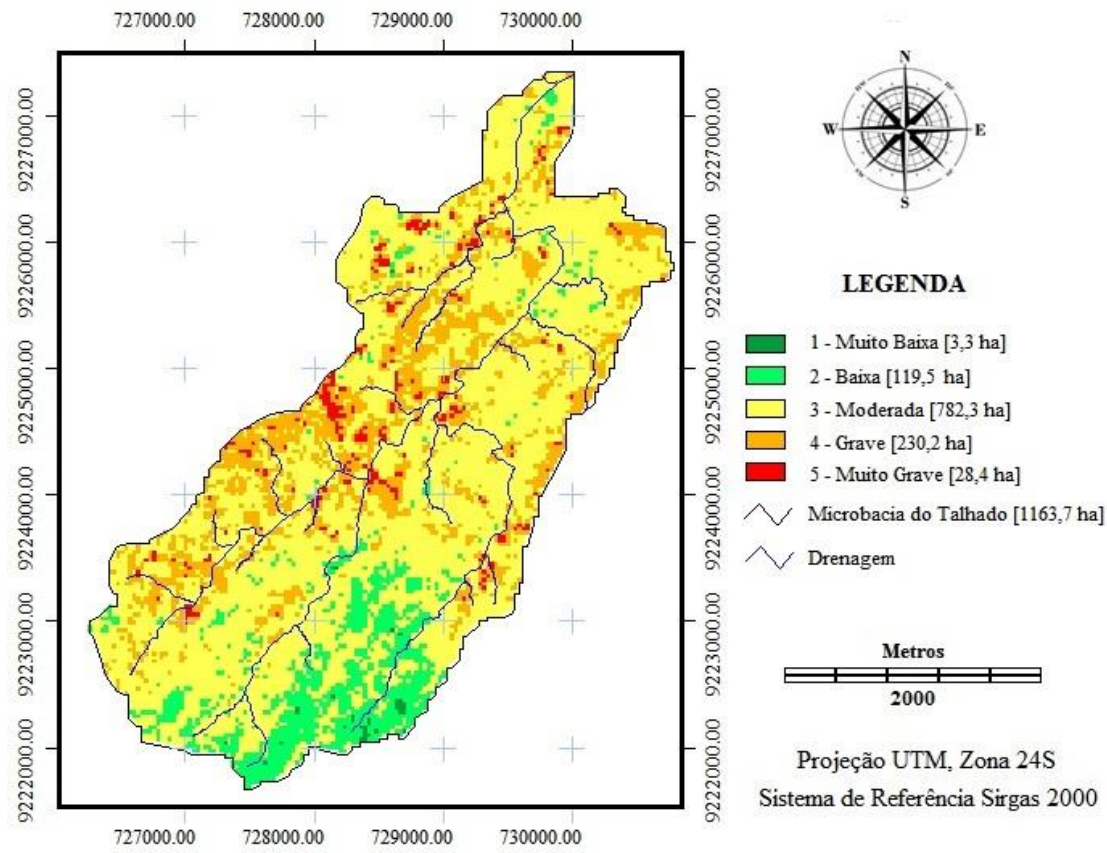

Figura 2. Mapa digital de vulnerabilidade ambiental segundo o NDVI_DIFERENÇA 2010/2013. Microbacia do Talhado/PB.

Tabela 6. Totais pluviométricos mensais no período de 2010 a 2013, média, máximas e mínimas no período de 20 anos, para o município de Santa Luzia, em mm.

\begin{tabular}{|c|c|c|c|c|c|c|c|c|c|c|c|c|c|}
\hline \multirow{2}{*}{ Ano } & \multicolumn{12}{|c|}{ Meses } & \multirow{2}{*}{$\begin{array}{l}\text { Total } \\
\text { anual }\end{array}$} \\
\hline & 1 & 2 & 3 & 4 & 5 & 6 & 7 & 8 & 9 & 10 & 11 & 12 & \\
\hline 2010 & 70,3 & 55,7 & 80,5 & 91,3 & 0,5 & 125,7 & 0 & 0 & 0 & 76,0 & 0 & 46,4 & 546,4 \\
\hline 2011 & 89,5 & 126,7 & 108,4 & 175,4 & 87,0 & 9,8 & 50,9 & 4,8 & 0 & 20,5 & 0 & 1,8 & 674,8 \\
\hline 2012 & 24,5 & 118,3 & 2,3 & 0 & 2,8 & 21,9 & 0 & 0 & 0 & 0 & 5,2 & 15,8 & 190,8 \\
\hline 2013 & 34,4 & 5,7 & 54,1 & 59,6 & 8,8 & 21,5 & 8,3 & 6,5 & 0 & 0 & 14,2 & 40,4 & 253,5 \\
\hline Média 20 anos* & 64,3 & 65,6 & 114,7 & 101,1 & 52,8 & 20,6 & 7,4 & 3,8 & 3,2 & 5,7 & 2,4 & 24,1 & 517,9 \\
\hline Máximo 20 anos & 384,4 & 256,6 & 366,3 & 263,2 & 158,4 & 125,7 & 50,9 & 31,6 & 34,4 & 76,0 & 14,2 & 115,8 & 885,8 \\
\hline Mínimo 20 anos & 0 & 5,7 & 2,3 & 0 & 0 & 0 & 0 & 0 & 0 & 0 & 0 & 0 & 136,4 \\
\hline
\end{tabular}

* 1994 a 2014. Fonte: AESA (2017)

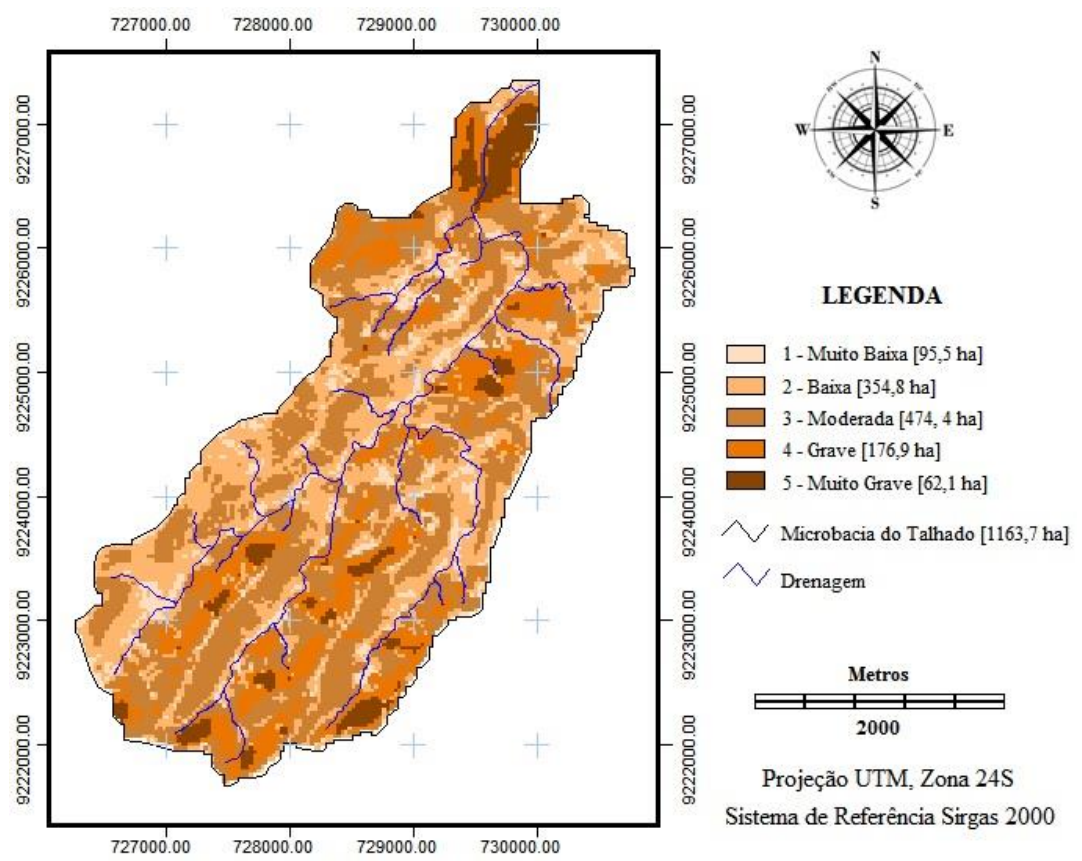

Figura 3. Mapa Digital de vulnerabilidade ambiental segundo o fator topográfico. Microbacia do Talhado/PB. 
Essa vulnerabilidade é provocada pela união das duas variáveis utilizadas no cálculo do LS (inclinação do relevo e o comprimento de rampa), que condicionam o escoamento de superfície e os processos erosivos (Coutinho et al., 2014). Sendo assim, faz-se necessário, medidas de conservação que promovam uma alta cobertura vegetal para compensar esse fator, principalmente nos locais da microbacia com alta susceptibilidade a erosão.

No que diz respeito a identificação das classes de uso das terras na microbacia estudada, é observado o predomínio das tipologias de caatinga arbustiva arbórea + algaroba (1086,8 ha - 93,39\% da área) em relação aos demais usos (Figura 4). Este dado é relevante para a região, pois a cobertura vegetal, contribui para o controle da erosão, das enchentes e para recarga do lençol freático na microbacia. Foi verificado "in loco" o uso dessas áreas, atribuindo-se valor baixo à moderado de vulnerabilidade ambiental.

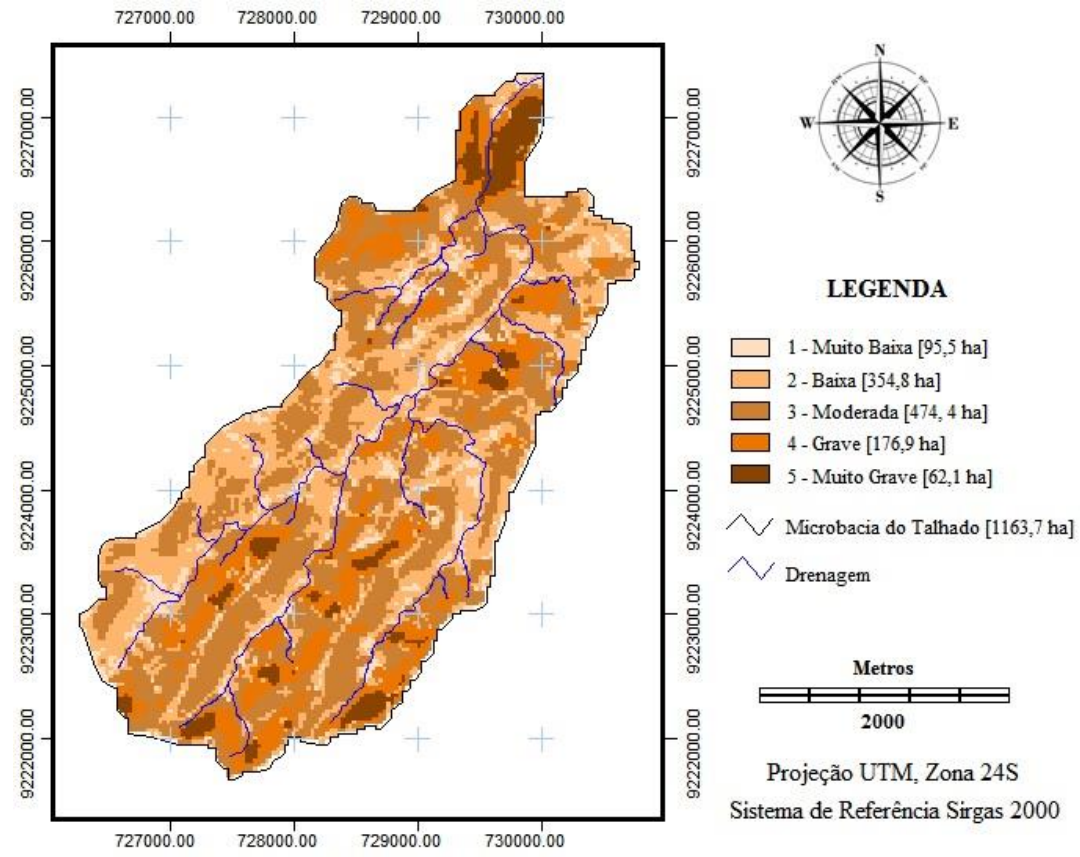

Figura 4. Mapa Digital de vulnerabilidade ambiental segundo o fator topográfico. Microbacia do Talhado/PB.

Verificou-se também que 46,3 ha $(3,98 \%)$ da área total estão ocupados com pastagem + agricultura (Figura 5) constituído por um pasto nativo formado pela retirada da vegetação nativa (caatinga) para a formação de campos sujos e por outra pequena parcela restante que está ocupada por pastagem plantada; enquanto na agricultura, que é essencialmente de subsistência, predominam o milho e o feijão. Contudo, 5,8 ha $(0,5 \%)$ ocupados por mineração de granito podem contribuir de forma bem mais significativa para o aumento da vulnerabilidade, principalmente pela poluição das águas superficiais por rejeito (Silva, 2014).

No mapa das APP's e uso restrito, ilustrado na Figura 6, podem-se verificar as APP's de drenos ocupando maior área $(115,4 \mathrm{ha})$, seguida pelas áreas de uso restrito $(67,7 \mathrm{ha}) \mathrm{e}$ declividade superior a $45^{\circ}$ (18,5 ha), enquanto as associações entre APP de dreno + área de uso restrito e APP de dreno + declividade acima de $45^{\circ}$ abrangem menores áreas, que representam 2,5 e 0,7 ha, respectivamente.

A influência das APP's de drenos está fisicamente limitada ao entorno dos seus cursos, contudo, elas garantem a estabilização de suas margens, evitando que o solo seja levado diretamente na forma de sedimentos para o ambiente aquático. Além disso, atuam também como um filtro que regula o fluxo de água superficial e subsuperficial e, consequentemente, do lençol freático das bacias hidrográficas (Brasil, 2012).
De acordo com o mapa do Índice de Vulnerabilidade Ambiental (IVA), 581,2 ha $(49,94 \%)$ do território possui vulnerabilidade moderada, seguida pelas áreas com vulnerabilidades baixa e muito baixa 541,5 ha $(46,53 \%)$, enquanto que 41,0 ha $(3,53 \%)$ variaram o grau de vulnerabilidade de grave a muito grave (Figura 6).

Nas áreas onde a vulnerabilidade foi classificada de muito baixa a baixa, observou-se ocupação antrópica reduzida, predominando nessas áreas cobertura vegetal (vegetação arbustiva arbórea aberta e vegetação arbustiva arbórea fechada) e afloramentos rochosos.

Nessas áreas, há predominância de relevo mais plano, podendo ser utilizado para uso mais intensivo (agricultura e pastagem), desde que observadas as práticas de conservação do solo e a legislação ambiental vigente (Silva, 2014; Brasil, 2012).

As áreas com vulnerabilidade moderada (maior parcela da área de estudo, com 581,2 ha) apresentaram maior percentual de agricultura, pastagem e extração mineral. Neta classe, também há a maior parcela das APP's de drenos (84,1 ha) e áreas de uso restrito (53,8 ha) e, principalmente, a ocorrência de relevo moderadamente ondulado a forte ondulado, onde essas áreas requerem práticas intensivas de conservação de solo, sendo por muitas vezes dispendiosas nas áreas com relevo mais acentuado (Ramalho Filho e Beek, 1995). 

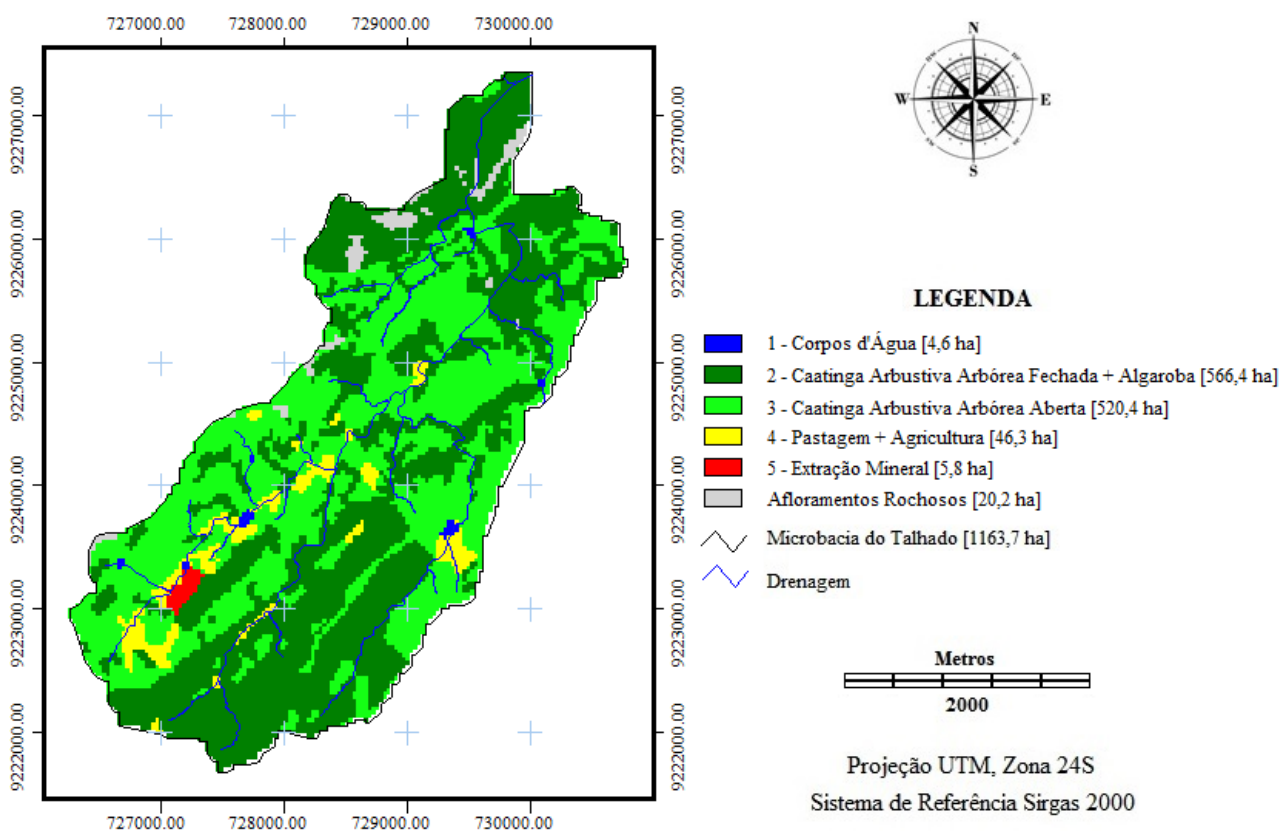

Figura 5. Mapa Digital de vulnerabilidade ambiental segundo o uso atual da terra. Microbacia do Talhado/PB.

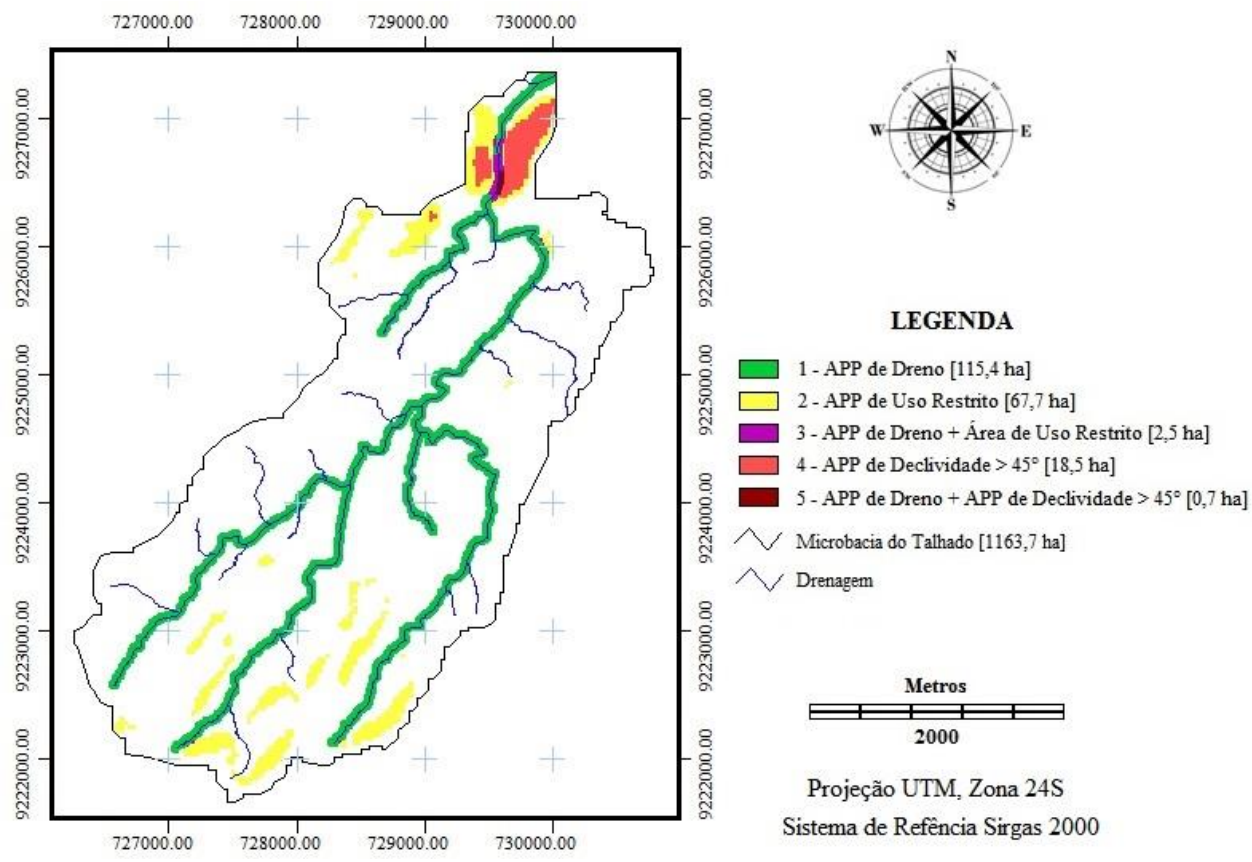

Figura 5. Mapa Digital de vulnerabilidade ambiental segundo as áreas legais e de uso restrito. Microbacia do Talhado/PB.

Portanto, recomenda-se, nestas áreas, a prática de agricultura e/ou pastagem na forma de sistemas agrosilvipastoris, culturas perenes ou manejo florestal, deste que respeitada a legislação ambiental vigente.

Nas áreas com vulnerabilidade variando de grave a muito grave, apesar de terem apresentado maior parcela com cobertura vegetal, foram identificadas áreas de uso antrópico (extração mineral, pastagem e agricultura) estando as mesmas em discordância com o grau de vulnerabilidade dessas classes.
Verificou-se, também, predominância de relevo forte ondulado a escarpado (APP de declividade) e a presença de APP de drenagem, tornando essas áreas de alta fragilidade para uso antrópico. Dessa forma recomenda-se cobertura vegetal permanente nessas áreas, podendo haver utilização para manejo florestal e atividades agrosilvipastoris nas áreas previstas pela legislação ambiental vigente, desde que observadas boas práticas agronômicas (Klais et al., 2012; Brasil, 2012) e o incentivo às atividades de turismo ecológico, favorecido pelas características cênicas da área. 

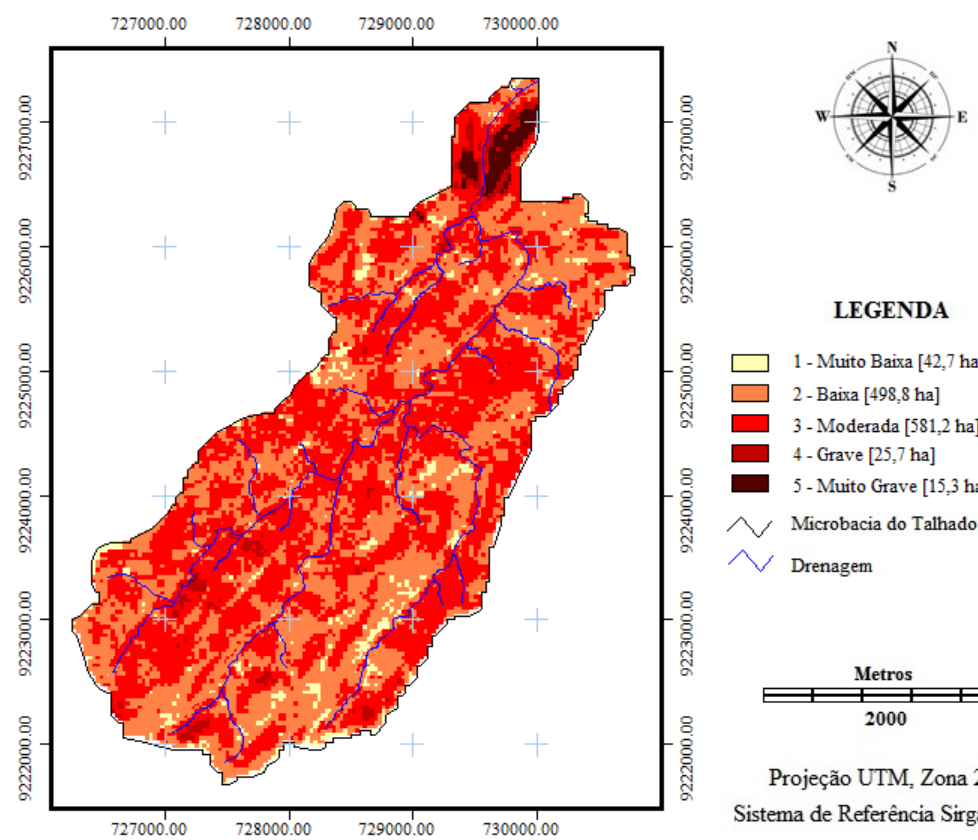

LEGENDA

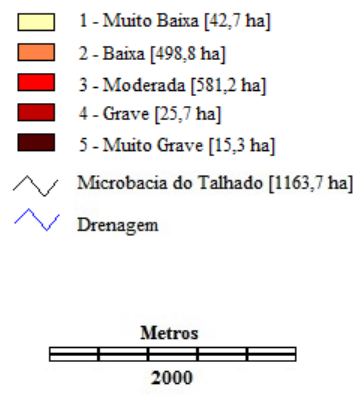

Projeção UTM, Zona 24S

Sistema de Referência Sirgas 2000

Figura 6. Mapa Digital de vulnerabilidade ambiental da microbacia do Talhado/PB.

\section{Conclusões}

A conformação geomorfológica local, com expressivas declividades do terreno, contribuiu para a indicação de áreas distribuídas nas classes grave e muito grave de vulnerabilidade;

O Índice de vulnerabilidade ambiental obtido, demonstra que as maiores classes de vulnerabilidade obtidas se situam entre moderada e muito grave, com a predominância de áreas de APP e de Uso restrito e nas áreas onde a vulnerabilidade foi classificada de muito baixa a baixa, observou-se ocupação antrópica reduzida, predominando nessas áreas cobertura vegetal.

Diante das condições limitantes de uso do solo, que respondem pelo grau de vulnerabilidade, sugerimos que sejam incentivadas a implementação de manejo florestal e atividades agrosilvipastoris nas áreas previstas pela legislação ambiental vigente, desde que observadas boas práticas agronômicas, incluindo o turismo ecológico.

\section{Referências}

Abdi, O. A.; Glover, E. K..; Luukanen, O. 2014. Causes and Impacts of Land Degradation and Desertification: Case Study of the Sudan. International Journal of Agriculture and Forestry, 3(2): 40-51 DOI: 10.5923/j.ijaf.20130302.03

AESA. Agência Estadual de Águas da Paraíba. Pluviometria Mensal - Posto de Santa Luzia-PB. Disponível em:. Acesso em: 10 jun. 2017.

Alvares, C. A.; Stape, J. L.; Sentelhas, P. C.; Gonçalves, J. L. de M.; Sparovek, G. 2014. Köppen's climate classification map for Brazil. Meteorologische Zeitschrift, v. 22, 711-728.

Alves, T. L. B.; Araújo, A. R.; Alves, A. N.; Ferreira, A. C.; Nóbrega, J. E. da. 2011. Diagnóstico Ambiental da Microbacia Hidrográfica do Rio do Saco, Santa Luzia - PB, Revista Brasileira de Geografia Física, Recife, v.4, n 2, p. 396-412. . Acesso em: 12 jun. 2017.

Bertoni, J.; Lombardi Neto, F. Conservação do Solo, 3. ed. São Paulo: Editora Ícone, 1990. 355p.

BRASIL. Decreto-Lei n ${ }^{\circ}$ 12.651, de 25 de maio de 2012.. Acesso em: 18 fev. 2015.
Coutinho, L. M.; Cecílio, R. A.; Garcia, G. O.; Xavier, A. C.; Zanetti, S. S.; Moreira, M. C. 2014. Cálculo do fator LS da Equação Universal de Perdas de Solos (EUPS) para a bacia do Rio da Prata, Castelo - ES. Revista Agro@mbiente On-line, 8(1): 01-09.

Durães, M. C. O.; Maia Filho, B. P.; Barbosa, V. V.; Figueiredo, F. P. de. 2017. Caracterização dos impactos ambientais da mineração a bacia hidrográfica do rio São Lamberto, Montes Claros/MG. Caderno de Ciências Agrárias, 9(1):49-61. Disponível.

Eastman, J.R. Idrisi 15: The Andes Edition. Worcester, MA: Clark University, 2016. 328p.

Klais, T. B. A.; Dalmas, F. B.; Morais, R. P.; Atique, G.; Lastoria, G.; Paranhos FILHO, A. C. 2012. Vulnerabilidade natural e ambiental do município de Ponta Porã, Mato Grosso do Sul, Brasil. Revista Ambiente \& Água, 7(2): 277-290.

Louzada, F. L. R. DE O.; Coutinho, L. M.; Andrade, C. C.; Oliveira, V. Á. DE S.; Breda, P. H. M.; Santos, A. R. dos. Análise da cobertura florestal por meio da subtração de imagem NDVI na Floresta Nacional de Pacotuba, Cachoeiro do Itapemirim, ES. In: Simpósio Brasileiro de Sensoriamento Remoto, 14., 2009, Natal. Anais... Natal: INPE, 2009. p 25-30.

Marcelino, R. L. 2012. Riscos e vulnerabilidades da bacia hidrográfica de Santa Luzia - PB. Tese de Doutorado Universidade Federal de Campina Grande, Campina Grande, Paraíba. 138p.

Melo, E. T.; Sales, M. C. L.; Oliveira, J. G. B. 2011. Aplicação do índice de vegetação por diferença normalizada (NDVI) para análise da degradação ambiental da microbacia hidrográfica do Riacho dos Cavalos, Crateús - CE. RA’'E GA, 23:520-533.

Melo, J. A. B. de; Lima, E. R. V. de. 2012. Uso da terra, vulnerabilidade e subsídios ao ordenamento territorial em microbacia. Mercartor, 11(24): 127-148.

Milanezi, C. H. da S.; Pereira, J. G. 2016. Caracterização da vulnerabilidade ambiental na microbacia do Córrego Azul, Ivinhema-MS. Geografia, 25(1): $43-63$.

Oliveira, P. T. S.; Rodrigues, D. B. B.; Alves Sobrinho, T.; Panachuki, E. Estimativa do fator topográfico da USLE a partir de três algoritmos. 2010. Revista Ambi-Agua, 5(2): 217-225.

Pinese Júnior, J. F.; Rodrigues, S. C. 2012. O Método de análise hierárquica -AHP- como auxílio na determinação da vulnerabilidade ambiental da bacia hidrográfica do rio Piedade (MG). Revista do Departamento de Geografia USP, 23:4-26.

Pons, N. A. D., Pejon, O. J. 2008. Aplicação do SIG em estudos de degradação ambiental: o caso de São Carlos (SP). Revista Brasileira de Geociências, 38(2): 295-302. 
Porto, M. F. A.; Porto, R. L. L. 2008. Gestão de bacias hidrográficas. Revista Estudos Avançados, 22(63):43-60.

Ramalho Filho, A.; Beek, K. J. Sistema de avaliação da aptidão agrícola das terras, 3 ed. Rio de Janeiro: EMBRAPA, 1995. 65p.

Rouse, J. W.; Hass, R. H.; Deering, D. W.; Schell, J. A. Monitoring the vernal advancement and retrogradiation (green wave effect) of natural vegetation. Austin: Texas A\&M University, 1974. 8p.

Silva, J. E. R. da. 2014. Diagnóstico físico-conservacionista, socioeconômico e ambiental em microbacia hidrográfica no Seridó paraibano. Dissertação de Mestrado, Universidade Federal de Campina Grande 141p.

Silva, R. M. P.; Lima, J. R. de; Mendonça, I. F.C de; 2014. Alteração da cobertura vegetal na sub-bacia do rio espinharas de 2000 a 2010. Revista Brasileira de Engenharia Agrícola e Ambiental, 18 (2) : 202 209

Silva, S. R. R.; Chaves, I. B.; Alves, J. J. A. 2010. Sensoriamento remoto e geoprocessamento aplicados ao zoneamento geoambiental: bacia hidrográfica do açude Camará - PB. Mercator, 9(20): 239-252.

Sousa, M. L. M de.; Nascimento, F. R. do; 2015. Estudos geoambientais de bacias hidrográficas em áreas susceptíveis à desertificação no Nordeste do Brasil. Cuadernos del Geografia, 24 (1): 13-42.

Wisner, B.; Blaikie, P.; Cannon, T.; Davi’s, I. At risk: natural hazards, peoples vulnerability an disasters, 2 ed. London and New York: Routhedge, 2004. 447 p.

Zanella, M. E.; Olímpio, J. L.; Eustógio, M. C. L. C.;Dantas, W. C. 2013. Vulnerabilidade socioambiental do baixo curso da bacia hidrográfica do rio Cocó, Fortaleza-CE. Sociedade e Natureza, 25 (2): 317- 332. 